REVISTA X, Curitiba, volume 14, n.3,p. 1-15, 2019.

\title{
ENTREVISTA COM APARECIDA DE JESUS FERREIRA
}

Interview with Aparecida de Jesus Ferreira

\author{
Aparecida de Jesus FERREIRA (UEPG) ${ }^{1}$
}

Aline BARBOSA (UFPR) ${ }^{2}$

Aparecida de Jesus Ferreira tem doutorado e pós-doutorado pela Universityof London na Inglaterra. É professora associada e pesquisadora da UEPG (Universidade Estadual de Ponta Grossa) no Estado do Paraná. Ministra aulas no curso de Letras para Graduação e Mestrado.

A autora tem dez livros publicados no Brasil e também um nos Estados Unidos, além dos artigos em periódicos ao redor do mundo. Atua na área de Linguística Aplicada, com ênfase em Formação de Professores, focando em temas que perpassam prática de ensino, ensino e aprendizagem de línguas, análise de livro didático e desenvolvimento de materiais de ensino, narrativas autobiográficas, letramento crítico e os processos de construção de identidades sociais (raça, gênero e classe social). Já foi chefe do Departamento de Línguas Estrangeiras Modernas na Unioeste (Universidade Estadual do Oeste do Paraná) e atuou como professora no Ensino Fundamental e Médio na Educação Básica.

Ferreira é um grande nome quando o assunto é pesquisa em Linguística Aplicada com foco em discussões sobre raça e identidade, e em seu site oficial é possível encontrar textos publicados que vão de 2006 a 2018. Seu trabalho luta pela representatividade positiva de indivíduos comumente marginalizados, em especial crianças em contexto escolar que tem no livro didático imagens de si deturpadas por conceitos provenientes de classes dominantes.

Aline: Você afirma que ter professoras/es e profissionais críticas/os que lidem com questões raciais requer consciência sobre suas próprias trajetórias ${ }^{3}$ e, no Brasil, vivemos um racismo mascarado e a falta de representatividade constante. Muitas vezes são anos

\footnotetext{
${ }^{1}$ Professora Doutora na Universidade Estadual de Ponta Grossa, UEPG.

${ }^{2}$ Mestre em Letras pela Universidade Federal do Paraná, UFPR.

${ }^{3}$ FERREIRA, 2011
} 
REVISTA X, Curitiba, volume 14, n.3,p. 1-15, 2019.

de reflexão até assumirmos nossa identidade racial negra. Como foi esse processo para você?

Aparecida: O processo de reconhecimento da sua própria identidade racial negra é algo muito complexo no Brasil, isso em razão de que se trata de um racismo mascarado. No contexto brasileiro, embora haja várias evidências, tanto do ponto de vista de pesquisa na área, como também evidências do que ocorre cotidianamente na vida das pessoas negras, de que o racismo existe e de que faz parte das experiências cotidianas das pessoas negras. No Brasil em vários segmentos sociais é negado de que o racismo ocorra cotidianamente na vida das pessoas negras. Dessa forma, assumir a identidade racial negra depende de vários fatores, desde o conhecimento sobre o tema, a educação recebida na família (que se reconhece como negra e tenha uma percepção de autoestima e de empoderamento da identidade racial negra), meios escolares (escolas, universidades, coletivos de negras/os), entre outros fatores.

No meu caso, o reconhecimento da minha identidade racial negra ocorreu em casa a partir das experiências de racismo que vi que ocorriam com a minha mãe no trabalho. Ocorreu também pela educação de autoestima ede empoderamento, poisminha mãe sempre me incentivou que eu gostasse da minha cor de pele e cabelo. Minha mãe sempre usou, dentro de casa, vários adjetivos afetivos e amorosos para a nossa cor de pele que fizesse com que eu e o meu irmão ficássemos orgulhosos. No entanto, passei a ler e a pesquisar mais sobre o assunto, em especial no momento em que entrei para a universidade e consolidei o meu conhecimento sobre as questões raciais. Já com alguns conceitos bem consolidados, isso fez com que eu assumisse e discutisse, debatesse sobre o tema com argumentos fundamentados.

O processo de assumir a minha identidade racial negra foi muito doloroso e ainda é na medida que me exponho e falo abertamente sobre o tema. Nesse sentido, sempre há questionamentos, tentativas de desconstrução e de deslegitimação do que eu digo publicamente acerca do tema em ambientes que não estão esperando que eu vá argumentar e discutir sobre a questão da identidade racial negra. Ou seja, sempre há olhares, posicionamentos dos corpos das pessoas e, algumas vezes, há aqueles que estão dispostos a ter uma discussão mais acalorada me dizendo: "Lá vem você de novo abordando sobre a questão racial". Esses que questionam/discordamagem como se eu não pudesse discutir e abordar sobre algo que me afeta cotidianamente, a exemplo de 
REVISTA X, Curitiba, volume 14, n.3,p. 1-15, 2019.

quando entro numa loja e sou seguida pelos vendedores -demonstrando uma preocupação que eu vá roubar algo da loja -, quando vou comprar determinado produto e tentam me vendar o mais barato, quando dão sugestões de como devo usar o meu cabelo, quando pessoas falam claramente que a minhas tranças deveriam ser substituídas por alisamentos ou mesmo quando falam que eu deveria cortar o meu cabelo, etc.

Esses que questionam/discordam agem como se eu tivesse que me calar sobre quando, por mais exemplos, vou a restaurante oua lugar mais sofisticado e há olhares de pessoas que não esperam ver o meu corpo naquele local. Sem contar as inúmeras vezes em que fui dar palestras em lugares em que o tema não era sobre a questão racial e as pessoas vinham procurar a palestrante e não conseguiam me ver como a pessoa que iria ministrar aquela palestra. Por exemplo, lancei recentemente o livro de literatura infantil "As Bonecas Negras de Lara". Então fui convidada para ir a uma escola particular para falar sobre o livro. Ao chegar na escola, a pessoa que veio me atender me perguntou: "O que você quer?". Eu disse: "Fui convidada para vir aqui para falar sobre um livro". A pessoa, é claro, não escutou ou não quis escutar o que eu disse e me falou: "Não temos livros aqui!". Eu repeti o que disse anteriormente, dessa vez mais alto e bem pausadamente. "EU FUI CONVIDADA PARA VIR AQUI PARA FALAR SOBRE O MEU LIVRO PARA AS CRIANÇAS DESTA ESCOLA!”. Ela abriu o portão e, com muita má vontade, me levou para falar com outra pessoa na escola. O que é importante ver aqui, nessa interação,são os modos como o corpo negro é recebido nos locais e isso fica evidente desde a tonalidade de voz, a polidez, o desejo de estar ou não com a pessoa, a boa vontade ou não e tantas outras maneiras de agir que eu poderia citar aqui que ocorreram naquela escola até o momento final, quando deixei a escola.

Falar sobre identidade racial negra e abordar como eu assumi essa identidade exige refletir sobre as experiências que me rodeiam cotidianamente, pois todos os lugares sociais em que circulo e todas as minhas relações sociais são mediados pela minha cor de pele, pela minha estética (cabelo, cor de roupas) e ainda sobre a minha voz e como eu falo - sempre assertivamente, sem rodeios e indo direto ao ponto. Ou seja, essas foram as formas como eu assumi e como foi constituída a minha identidade racial de mulher negra. 
REVISTA X, Curitiba, volume 14, n.3,p. 1-15, 2019.

Aline: Seus textos falam sobre pessoas negras e suas vivências no contexto de sala de aula, enquanto professoras/es de línguas e também enquanto alunas/os. Tendo em vista que você mora no Sul do país, uma região famosa por estereótipos fortemente ligados a questões de racismo, como é falar de raça no contexto no qual está inserida?

Aparecida: A região em que eu moro atualmente é Ponta Grossa (já por 10 anos) e a região em que morei anteriormente é Cascavel (por 42 anos). Ambas são regiões cuja população é constituída majoritariamente por eurodescendentes, com cerca de 20 por cento apenas de população afrodescendente. Abordar assuntos relacionados a questões de identidade racial negra é um desafio ainda maior do que no restante do Brasil. Com isso quero dizer que o racismo também ocorre em regiões com uma população majoritariamente negra, como é o caso do Sudeste, do Nordeste e do Norte do Brasil. As pesquisas demonstram que o tratamento dado à população negra no que se refere ao acesso à escola, àmoradia, àassistência médica, a emprego e a cargos de poder não difere significativamente nas diversas regiões do Brasil. Com isso quero dizer que o racismo é endêmico no Brasil, independentemente da região em que nós, negras/os, estejamos.

Há, no entanto, uma diferença de percepção. As pessoas da região onde atuei e atuo no momento tendem a pensar que tratar da questão de identidades raciais negras é desnecessário, pois a região é majoritariamente habitada por pessoas brancas. Esse argumento, porém, não se sustenta - não se sustenta na medida em que as pessoas que moram na regiãoconvivem com a população que é, de fato, multiétnica e multirracial, o que necessariamente vai gerar diversidade em muitos contextos familiares, nas escolas, nos diversificados ambientes de trabalho e nas interações sociais em geral. As pessoas mudam de região e também nos novos locais há uma comunidade diversa que precisa ser respeitada, ou seja, tratar da questão da diversidade racial é uma obrigação e uma necessidade para que tenhamos de fato uma sociedade mais justa, com equidade e igualitária. Por exemplo, na região dos Campos Gerais, há várias comunidades quilombolas- quatro em Castro e duas em Ponta Grossa. No Paraná, há 37 comunidadesquilombolascertificadas pela Fundação Palmares. São, em verdade,socialmente invisibilizadas, ou seja, não recebem a mesma atenção concedida às comunidades eurodescendentes, como é o caso, por exemplo, do Parque Histórico de Carambeí - de colonização holandesa. Essas comunidades mencionadas são parte do 
REVISTA X, Curitiba, volume 14, n.3,p. 1-15, 2019.

patrimônio cultural brasileiro (afrodescendentes e eurodescendentes) e estão na mesma região, no entanto, com estereótipos diferenciados. Os estereótipos relativos à população eurodescendente fortalecem a sua identidade racial branca, enquanto os estereótipos relativos à população afrodescedente descaracterizam, fragilizam e desconstroem a autoestima da identidade racial negra.

Abordar a questão da identidade racial negra nesse contexto e sobre ele exige persistência e, pensando do local em que atuo, há necessidade de formação crítica de professoras/es e de alunas/os. Essa formação crítica é indispensável para que seja possível tratar do racismo e das várias identidades raciais e, assim, pensar na "construção" de uma sociedadeque esteja disposta à integração de todas as raças de forma igualitária, com equidade e humanidade.E para que isso seja possívelprecisamos ver na região mais médicas/os negras/os, mais professoras/es negras/os, arquitetas/os, engenheiras/os, e que os cargos e as posições de poder sejam também distribuídos para todos os segmentos sociais e raciais com equidade, para que as pessoas de todospertencimentos étnico-raciais se possam ver representadas.

Aline: Considerando questões de prestígio e de capital cultural, segundo Bourdieu (1977, 1984), como o assunto "raça" pode ser visto como um tema tabu e sua posição enquanto mulher e negra. Em algum momento de sua carreira acadêmica você teve receio de falar sobre raça?

Aparecida: Como mencionado na pergunta, a obra do filósofo e sociólogo francês Pierre Bourdieu colabora muito com a reflexão sobre as questões raciais, pois, atravésda sua visão sobre a questão dos "capitais" - econômico, social, cultural e simbólico -, ele nos alerta para o quanto isso impacta na questão de identidade racial negra interseccionadacom as questões de gênero e de classe social. Assim, cabe mencionar o capital econômico, ou seja, eu vim de uma família pobre, filha de mãe solteira. Quanto ao capital cultural que foi me repassado pela minha família, e que é parte do patrimônio cultural brasileiro - no entanto não considerado como importante no contexto brasileiro -, esse foi o que me possibilitou ver que era pelo estudo que eu conseguiria adquirir uma "certa liberdade de lugar de fala" e mobilidade social, que minha mãe, por exemplo, teve muito mais dificuldade de ter. Já com relação ao capital social, conquistado mediante a realização de cursos de inglês, obter acesso a boas bibliotecas (e 
REVISTA X, Curitiba, volume 14, n.3,p. 1-15, 2019.

tempo para ler, pois minha mãe fez o possível e o impossível para que eu tivesse tempo para estudar), acesso a boas escolas, acesso a uma excelente universidade pública na graduação eno mestrado,além de alcançar condições de ter feito doutorado e pósdoutorado fora do Brasil (Inglaterra). Isso tudo me possibilitou ter a certeza de que teria empecilhos com relação a tratar do tema da identidade racial negra, mas, por outro lado, essas minhas experiências mediadas, por uma sólida formação como pesquisadora, me deram a certeza de que era essa a minha contribuição que eu poderia dar para a Educação e Educação Linguística e na área da Linguística Aplicada no Brasil.

Eu sou a primeira pesquisadora negra na área de Língua Inglesa a ter publicações com o tema de Identidades Sociais de Raça Negra no Brasil (formação de professoras/es, livro didático, letramento racial crítico). E isso me deixa muito feliz, porque, assim como as minhas pesquisas, muitas/os outras/os pesquisadoras/es estão encontrando seus lugares como pesquisadoras/es no contexto brasileiro e fora do Brasil. Ter receio de abordar assuntos sobre a questão racial interseccionada com as questões de gênero e de classe social, seja no contexto atual ou em outros momentos históricos, sempre foi uma questão e um desafio para as pessoas comprometidas com questões de inclusão da população negra no Brasil.

Aline: Você tem extensivo trabalho que aborda trajetórias e narrativas de si partindo de professoras/es e estudantes negras/os. Pela minha experiência pessoal, enquanto pesquisadora iniciante, às vezes é difícil reunir indivíduos negros dispostos a participar de uma pesquisa em que eles estejam no holofote. Você já chegou a passar por isso? Se sim, a que atribui essa situação?

Aparecida: A questão de ter professoras/es e estudantes negras/os interessados em participar de pesquisas precisa ser entendida de várias formas.

Em primeiro lugar, abordar o tema em público é algo doloroso para muitas negras e para muitos negros, pois faz relembrar situações que ocorrem cotidianamente de forma que desprivilegiama sua existência - isso não é algo simples nem desconsiderável.

Em segundo lugar, para que se possa obter colaboração há que fazer com que se sintam parte do processo da pesquisa, ou seja, com que percebam que algo será devolvido para as pessoas negras por essa participação. As pessoas precisam se ver 
REVISTA X, Curitiba, volume 14, n.3,p. 1-15, 2019.

como parte da pesquisa e o retorno é algo importante. O que tento fazer nas minhas pesquisas é envolver as pessoas e perguntar para elas o que gostariam que fosse dado como retorno para elas/es que participaram daquela pesquisa.

Em terceiro lugar, as pesquisas que faço envolvem, de alguma forma, produção, análise, avaliação de materiais didáticos ede narrativas autobiográficas, tanto de professoras/es como de estudantes. A participação é essencial para entender a pesquisa e os dados gerados através de entrevistas individuais ou de grupo focal, produção de materiais, questionários, observações, cadernos de anotações. A geração dos dados faz parte do processo e os participantes se sentem envolvidos em todas as etapas da pesquisa e opinam com relação às reflexões e aos resultados. Ademais, podemas/os participantes/colaboradoras/es da pesquisa inserir temas que são do interesse deles e delas também acaba sendo um motivador para a participação.

Em quarto lugar, a questão de trazer a voz de pessoas negras para o centro da pesquisa precisa também envolver o convencimento da importância da participação e o quanto as suas narrativas, participação, experiências podem colaborar para que muitos de nós não passemos por experiências que sejam dolorosas, que nos desqualificam, que nos colocam à margem.Asparticipações em pesquisas que abordam a questão racial podem, sim, nos empoderar, aumentar a nossa autoestima e também empoderar outras e outros ao nosso redor. Outra questão é que as pesquisas sobre pessoas negras precisam considerar as pessoas não somente falando sobre o racismo, mas sobre outras questões das suas vidas.

$\mathrm{E}$, finalmente, mostrar pesquisas similares ao que estou propondo e mostrar os impactos de tais pesquisas na vida das pessoas negras é algo que também motiva a participação. As dificuldades existem. Então entendo as posições das pessoas negras que algumas vezes não querem participar das pesquisas em que elas estejam no holofote. Para alterar isso, estratégias precisam ser usadas para que elas se sintam parte do processo, possam opinar e que os dados gerados a partir da participação sejam discutidos com os participantes e divulgados com a sua permissão. Essas têm sido as reflexões que tenho feito a partir das minhas experiências como pesquisadora acerca de identidades sociais de raça negra.

Aline: Em alguns artigos, você cita o papel do/a educador/a como fundamental para "não promover o sentimento de inferioridade da criança negra em relação ao material 
REVISTA X, Curitiba, volume 14, n.3,p. 1-15, 2019.

que está utilizando e nem fazer com que a criança branca crie uma aversão ou qualquer espécie de preconceito com outras etnias" ". Como você acha que um/a professor/a pode reverter a possível falta de representatividade em materiais didáticos, em sua prática de sala de aula e na escola?

Aparecida: Os livros didáticos para o uso de professoras/es de línguas são instrumentos importantes para a utilização noensino-aprendizagem. Considerando que um/a professor/a, atualmente, para sobreviver com um salário suficiente, ministra mais de 40 horas semanais, esse/a professor/acertamente não consegue preparar 40 horas semanais sem um apoio de horas/atividade remuneradas e sem ter formação continuada. A alternativa para esse/a professor/a é, então, trabalhar comlivro didático. O que preciso enfatizar aqui é que se esse/a professor/a tivesse horas atividades remuneradas para preparar seu próprio material didático não precisaria de um livro didático.

O livro didático é um material importante para o/a professor/a, mas precisa que o/a professor/a queirá utilizar tenha uma formação crítica para questionar o livro didático e outros materiais didáticos e propor sugestões para os mesmos. No que se refere ao livro didático, o que as pesquisas têm demostrado (FERREIRA, 2014) é que os materiais são extremamente eurocêntricos, mesmo com a quantidade de pesquisas que vêm sendo feitas, mostrando o que as editoras poderiam fazer para que a representatividade de pessoas negras, indígenas, de classe social e de gênero fosse mais equitativa e igualitária. Como isso não ocorre, por questões ideológicas e de interesse das editoras a formação de professoras/es é de fundamental importância.

O/a professor/a, ao utilizar um livrodidático ou outro material didático,pode reverter amencionada falta de representatividade, trabalhando com o letramento racial crítico em sala de aula. Isso significa realizar um trabalho docente que traga reflexões para o contexto de sala de aula e mostre, no livro didático, como a representação de pessoas negras, indígenas, de gênero e de classe social não está de acordo com a representação de quem de fato utiliza os livros didáticos.As/os alunas/os precisam se ver nos materiais didáticos que utilizam. Ao fazerem, por exemplo, uma simples constatação,em sala de aula, dealunas/ose as suas identidades de raça, de gênero e de classe social e comparar os dados com o que está representado no livro didático,logo perceberão a diferença gritante de representatividade entre pessoas negras e brancas.

\footnotetext{
${ }^{4}$ FERREIRA \& FERREIRA, 2011, p. 118.
} 
REVISTA X, Curitiba, volume 14, n.3,p. 1-15, 2019.

Basta verificar as imagens (desenhos, pinturas ou fotografias) que aparecem nos livros didáticos.

Essa reflexão conjunta de professor/a e alunos/as certamente explicita a dimensão de que as representações não são equitativas nem igualitárias e essa descoberta pode provocar, nas/os alunas/os, um processo de letramento racial crítico e também as suas interseções com gênero e com classe social.Para que, no entanto, possa ser realizado o que foi sugerido, o/a professor/a precisa ter passado por uma formação de professores que permita que ele/a possa ver isso e então abordar em sala de aula. A formação crítica do/aprofessor/a é de crucial importância para que consigamos avançar na desconstrução dos vários estereótipos dos materiais didáticos eurocêntricos.

Aline: Você tem experiência na Linguística Aplicada, atuando com formação de professores/as e com temas como os processos de construção de identidades sociais (raça, gênero e classe social) e letramento racial crítico direcionado à sala de aula também de línguas estrangeiras. Pensando no retrógrado momento político em que nos encontramos, e na caça às bruxas promovida contra educadores/as, como essas teorias podem informar o trabalho deste profissional?

Aparecida: O que tenho defendido e entendo como Letramento Racial Crítico é:

Letramento racial crítico é refletir sobre raça e racismo, e nos possibilita ver
o nosso próprio entendimento de como raça e racimo são tratados no nosso
dia a dia, e o quanto raça e racismo têm impacto em nossas identidades
sociais e em nossas vidas, seja no trabalho, no ambiente escolar,
universitário, em nossas famílias, nas nossas relações sociais. [...]. Como
formadora de professoras/es que sou, entender a importância de utilizar o
letramento racial crítico na minha prática pedagógica é de extrema relevância
para que assim possa também colaborar para que tenhamos uma sociedade
mais justa, com igualdade e com equidade. (FERREIRA, 2015, p. 138).

Falar, abordar, tratar do letramento racial crítico para o/a profissional que quer uma educação mais justa, igualitária e equitativa faz parte da sua prática pedagógica, dos textos escolhidos, das atividades que são desenvolvidas em sala de aula. Não há como um/a profissional, no momento histórico atual, tratar de qualquer questão sem considerar as identidades sociais envolvidas no processo. Explico: se estamos ensinando, educando, atendendo nossas/os alunas/os, seja em sala de aula, seja em orientações de TCC, de mestrado ou de doutorado, há pessoas envolvidas e que interagem com outras pessoas - isso impacta a vida delas e as nossas. 
REVISTA X, Curitiba, volume 14, n.3,p. 1-15, 2019.

O/A profissional, não somente da área da educação, mas em todas as outras áreas do conhecimento, tem que considerar as pessoas que atende e com elas interage, considerando sempre as complexidades que perpassaram e perpassam a formação das suas identidades sociais de raça, de gênero de classe social. Ou seja, o letramento racial crítico, de forma interseccionada, está imbricado nas relações sociais. Os/As profissionais que não estão levando isso em consideração estão deixando de atender, deixando de educar as pessoas na sua totalidade. Isso, porém, é um dever de cada profissional e é o esperado de quem é atendido. Para que as relações sociais sejam plenamente humanizadas, esse letramento racial crítico precisa passar pelo processo de uma educação formal. E não há como interagir com as pessoas de forma humanizada sem ter as individualidades no centro da questão.

Aline: Em diversos trabalhos que foram publicados ao longo dos últimos anos, você comenta como o livro didático "apresenta identidades fixas e homogêneas e que não condizemcom as realidades dos alunos" (SANTA CLARA e FERREIRA, 2018, p. 86). Embora representações mais plurais estejam em falta, você consegue sentir algum avanço em termos de representatividade no âmbito escolar quando compara o material produzido atualmente com o usado durante os anos em que foi aluna da Educação Básica?

Aparecida: Ao se abordar, atualmente, a questão dos livros didáticos, é sempre importante refletir sobre os avanços que tivemos nos últimos anos e que foram vários. Não podemos, entretanto, deixar de refletir também sobre o que ainda precisamos avançar. Por exemplo, temos o Programa Nacional do Livro Didático - PNLD, que trouxe vários avanços. No período em que eu era estudante da Educação Básica não existia o PNLD, que passou a existir em 1996 e, no caso da área de línguas estrangeiras/adicionais, a primeira publicaçãofoi em 2011. Um dos avanços produzidos a partir do PNLD é que há um cuidado e um monitoramento para que os livros didáticos não apresentem formas de racismo, de preconceito, de discriminação nos livros didáticos, entre outras questões.

Os livros didáticos certamente hoje têm uma representatividade de pessoas muito maior do que quando eu era aluna. No entanto, o que as pesquisas sobre o livro didático têmdemonstrado (FERREIRA, 2012, 2014, 2019 no prelo), ou seja, que a representação das pessoas negras interseccionada com gênero e classe social ainda deixa 
REVISTA X, Curitiba, volume 14, n.3,p. 1-15, 2019.

muito a desejar do que é considerado adequado para que as pessoas negras que vivem no Brasil se sintam representadas de forma equitativa. No Brasil hoje a população de negras/os (pretos e pardos),de acordo com os últimos censos, é mais de $54 \%$ da população.Ocorre que os livros didáticos estão longe de refletirem uma equivalência com essa realidade. Uma pesquisa minha em 2012 - no livro didático de inglês mais vendido na época no Brasil - apresentou o seguinte:

Representações de brancos, asiáticos e negros

\begin{tabular}{|c|l|c|c|c|}
\hline Atributos & \multicolumn{1}{|c}{ Branco } & Asiático & \multicolumn{1}{c|}{ Negra } & Total \\
\hline Homem & $321(89,6 \%)$ & $13(3,6 \%)$ & $24(6,7 \%)$ & $358(100 \%)$ \\
\hline Mulher & $246(88,1 \%)$ & $20(7,1 \%)$ & $13(4,6 \%)$ & $279(100 \%)$ \\
\hline & $567(89 \%)$ & $33(5,1 \%)$ & $37(5,8 \%)$ & $637(100 \%)$ \\
\hline
\end{tabular}

Fonte: FERREIRA, Aparecida de Jesus. Identidades sociais de raça no livro didático de Inglês mais vendido no Brasil. In: HARMUCH, Rosana Apolônia; SALEH, PascoalinaBailon de Oliveira. Identidade e subjetividade: configurações contemporâneas. 1. ed. Campinas, SP: Mercado de Letras, 2012b, v. 1, p. 99-114.

Já uma outra pesquisa, essa realizada por Dambrós em 2016, apresentou os seguintes dados:

Dados sobre Livro didático e Identidades Sociais de Raça e Classe Social

\begin{tabular}{|c|c|c|c|c|}
\hline $\begin{array}{l}\text { Profissões/ } \\
\text { Atividades }\end{array}$ & $\begin{array}{l}\text { Livro de Inglês como } \\
\text { Língua Adicional } \\
\text { (PNLD - 2012-2015) }\end{array}$ & $\begin{array}{l}\text { Foto e imagem: } \\
\text { pessoas negras } \\
\text { (homens, } \\
\text { mulheres, } \\
\text { crianças e } \\
\text { adolescentes) }\end{array}$ & $\begin{array}{l}\text { Foto e imagem: } \\
\text { pessoas brancas } \\
\text { (homens, } \\
\text { mulheres, } \\
\text { crianças e } \\
\text { adolescentes) }\end{array}$ & Total \\
\hline Laser & $\begin{array}{l}\text { On Stage, Take Over, } \\
\text { Freeway, Up Grade - } \\
\text { PNLD 2012. Alive } \\
\text { High, High Up, Take } \\
\text { Over - PNLD } 2015\end{array}$ & $68=29 \%$ & $168=71 \%$ & $236=100 \%$ \\
\hline Esportes & $\begin{array}{l}\text { On Stage, Take Over, } \\
\text { Freeway, Up Grade - } \\
\text { PNLD 2012. Alive } \\
\text { High, High Up, Take } \\
\text { Over - PNLD } 2015\end{array}$ & $33=38 \%$ & $55=62 \%$ & $86=100 \%$ \\
\hline Família & $\begin{array}{l}\text { On Stage, Take Over, } \\
\text { Freeway, Up Grade - } \\
\text { PNLD 2012. Alive } \\
\text { High, High Up, Take } \\
\text { Over - PNLD } 2015\end{array}$ & $67=16 \%$ & $324=84 \%$ & $408=100 \%$ \\
\hline Profissões & $\begin{array}{l}\text { On Stage, Take Over, } \\
\text { Freeway, Up Grade - } \\
\text { PNLD 2012. Alive } \\
\text { High, High Up, Take } \\
\text { Over - PNLD } 2015\end{array}$ & $24=20 \%$ & $93=80 \%$ & $117=100 \%$ \\
\hline Trabalho & On Stage, Take Over, & $83=27 \%$ & $218=73 \%$ & $301=100 \%$ \\
\hline
\end{tabular}


REVISTA X, Curitiba, volume 14, n.3,p. 1-15, 2019.

\begin{tabular}{|l|c|c|c|c|}
\hline Intelectual & $\begin{array}{c}\text { Freeway, Up Grade - } \\
\text { PNLD 2012. Alive } \\
\text { High, High Up, Take } \\
\text { Over - PNLD 2015 }\end{array}$ & & & \\
Total & & $275=24 \%$ & $873=76 \%$ & $1148=100 \%$ \\
\hline
\end{tabular}

Fonte: Compilação dos dados feita por Aparecida de Jesus Ferreira, a partir da pesquisa de Dambrós(2016). Disponível em: DAMBRÓS, Lilian Paula. Construção das identidades sociais de raça com intersecção de classe nos livros didáticos de Inglês do ensino médio aprovados pelos PNLDs 2012 e 2015. 2016. Dissertação (Mestrado em Linguagem, Identidade e Subjetividade) - Universidade Estadual de Ponta Grossa - UEPG, Ponta Grossa/PR, 2016.

O que os resultados das pesquisas apresentadas nas duas tabelas acima demonstram é que ainda temos muito para avançar para que a população negra esteja representada nos livros didáticos de Língua Inglesa de forma equitativa. Ou seja, é inaceitável que em um país com uma população negra de $54 \%$, somente tenha uma representação no livro didático de $24 \%$ da população negra, como demonstrado na segunda tabela (DAMBRÓS, 2016), enquanto, 76\% da população representada seja branca. O livro didático também representa o patrimônio cultural brasileiro, e que é formado por pessoas negras e brancas e precisa ser equitativa essa representação. As pesquisas retratadas aqui foram na área de Língua Inglesa, masoutras pesquisas em outras áreas têmdemonstrado resultados similares (ONIESKO, 2017).Quando vamos descompactar os dados demonstrados das tabelas mencionadas (FERREIRA, 2012; DAMBRÓS, 2016), e ver como as pessoas negras são representadas, mesmo estando em um número menor de pessoas, são as pessoas negras que aparecem sendo representadas de forma estereotipada, com menos prestígio social, exercendo papéis que não são representadas como intelectualizadas. Precisamos de muito mais pesquisas na área e que sejam publicadas para que assim possamos, de fato, sensibilizar, humanizar as editoras, escritoras/es, avaliadoras/es de livros didáticos, para que percebam o desequilíbrio e a falta de representatividade dos papéis sociais exercidos pelas pessoas negras e brancas nos livros didáticos.

Aline: Além de raça, seus estudos envolvem gênero, apontando para a importância de se pensar na questão da identidade interseccionada. Como você enxerga o papel do gênero nas discussões sobre raça?

Aparecida: Nas pesquisas sobre as questões de identidades sociais de raça não há como não refletir sobre essa questão sem que seja de forma interseccionada, pois a mulher 
REVISTA X, Curitiba, volume 14, n.3,p. 1-15, 2019.

negra está na base da pirâmide em todos os sentidos - com menos acesso à escola, sofre mais violência doméstica e sexual, tem o pior atendimento médico, ganha o menor salário e tem menos acesso a [posições sociais e históricas de] poder. Sendo assim, pensar em uma educação linguística exige a reflexão de que as pessoas precisam se tornar mais críticas acerca do que ocorre na sociedade.

Desse local em que atuo, que é a formação de professoras/es, o que podemos fazer é promovermelhorescondições para as mulheres na sociedade brasileira e essa promoção passa pela educação e pela crítica dos discursos produzidos sobre o que é ser mulher e negra na sociedade brasileira, de forma interseccionada (raça, gênero, classe social, idade).Na educação linguística crítica é exatamente o que fazemos, analisamos discursos produzidos e produzimos discursos nas suas mais diversas modalidades.

Aline: Você é uma professora e pesquisadora reconhecida, que produziu e segue produzindo material intelectualsignificativo abordando questões que, por vezes, são deixadas de lado. Que conselho você daria a uma pessoa que tem interesse em se aprofundar em questões de raça?

Aparecida: As minhas sugestões são que procurem por grupos de pesquisas que estejam pesquisando na área, hoje no Brasil e fora do Brasil há um contingente importante de pesquisadoras/es abordando a temática racial em todas as áreas do conhecimento. As universidades brasileiras (federais, estaduais e privadas) têm Núcleos de Estudos Afro-Brasileiros, mas de 150 núcleos em todo Brasil e fora do Brasil também há um contingente importante e que estão todos disponíveis nas plataformas on-line das universidades.

Há também várias pesquisas disponíveis online seja através do portal virtual da CAPES de teses e de dissertações, como também artigos disponíveis no Google Acadêmico e em outros portais como por exemplo, Reserchgate, AcademiaEdu, em periódicos abertos que estão localizados nas várias universidades do Brasil, e também no SCIELO.

Há muitas lacunas de pesquisas que precisam ser preenchidas precisamos de mais pesquisadoras/es interessadas/os na questão racial e estamos disponíveis para colaborar, ajudar e participar. Sejam todas e todos bem vindas/os. 
REVISTA X, Curitiba, volume 14, n.3,p. 1-15, 2019.

Aline: Você gostaria de mencionar mais alguma coisa que não surgiu até o momento na entrevista e é importante dentro de seu trabalho?

Aparecida: Em primeiro lugar, eu gostaria de agradecer estaoportunidade de poder responder às importantes questões que me foram formuladas. Foram questões muito pertinentes e prazerosas, bem como me suscitaram também várias reflexões a mais sobre a temática. Obrigada, Aline, pelas perguntas, e agradecimentos à Revista X, pela oportunidade.

O que eu talvez gostaria de mencionar é que as/os pesquisadoras/es com temas relativos as questões de identidades sociais de raça e suas interseccionalidades, ao produzirem seus artigos para publicações em periódicos e em livros, também tentem mostrar outras possibilidades de que as pesquisas cheguem às/aos professoras/es da educação infantil, do ensino fundamental e do ensino médio, pois é cada vez mais evidente o distanciamento entre as universidades e as escolas da Educação Básica.

\section{REFERÊNCIAS}

DAMBRÓS, L.P. Construção das identidades sociais de raça com intersecção de classe nos livros didáticos de inglês do ensino médio aprovados pelos PNLDs 2012 e 2015. 2016. Dissertação (Mestrado em Linguagem, Identidade e Subjetividade) -Universidade Estadual de Ponta Grossa - UEPG, Ponta Grossa/PR, 2016.

FERREIRA, A.J. Addressing racelethnicity in Brazilian schools: a critical race theory perspective. Seattle - USA: CreateSpace, 2011.

FERREIRA, A.J. Percepções de professores de línguas sobre o processo de produção de materiais de ensino. LLJournal - CUNY - N.Y. - USA., v. 6, 2011.

FERREIRA, A.J.; FERREIRA, S.A. Raça/etnia, gênero e suas implicações na construção das identidades sociais em sala de aula de línguas. RevLet - Revista Virtual de Letras, v. 03, n.2, p. 114-129. ago./dez. 2011.

FERREIRA, A.J. Identidades sociais de raça no livro didático de Inglês mais vendido no Brasil. In: HARMUCH, R.A.; SALEH, P. B.O. Identidade e subjetividade: configurações contemporâneas. Campinas, SP: Mercado de Letras, 2012.,v. 1, p. 99114.

FERREIRA, A.J. (Org.). As políticas do livro didático e identidades sociais de raça, gênero, sexualidade e classe em livros didáticos. Campinas, SP: Pontes Editores, 2014.

FERREIRA, A.J. Letramento racial critico através de narrativas autobiográficas: com atividades reflexivas. Ponta Grossa, PR: Editora Estúdio Texto, 2015. 
FERREIRA, A.J. Social Identities of Black Females in English Language Textbooks used in Brazil and Cameroon: intersectionalities of race, gender, social class and critical racial literacy. Revista X, Dossiê Especial: Existimos e Resistimos, 2019 (no prelo).

ONIESKO, P. C.F..A identidade negra nas imagens do livro didático de história através do olhar dos/as alunos/as. 2018. Dissertação (Mestrado em Estudos da Linguagem), Universidade Estadual de Ponta Grossa - UEPG, Ponta Grossa/PR, 2018.

SANTA CLARA, M. P.; FERREIRA, A.J. Identidades sociais de gênero com intersecção de raça e de classe no livro didático de Língua Inglesa: o que as pesquisas recentes revelam. UniLetras, v. 39, n. 1, p. 75-89, 2018. 